CLINICAL STUDY

\title{
Assessment of glucocorticoid therapy with salivary cortisol in secondary adrenal insufficiency
}

\author{
Filippo Ceccato, Nora Albiger, Giuseppe Reimondo ${ }^{1}$, Anna Chiara Frigo ${ }^{2}$, Sergio Ferasin, Gianluca Occhi, \\ Franco Mantero, Massimo Terzolo ${ }^{1}$ and Carla Scaroni \\ Endocrinology Unit, Department of Medicine DIMED, University of Padova, Via Ospedale Civile, 105, 35128 Padova, Italy, ${ }^{1}$ Internal Medicine 1, \\ Department of Clinical and Biological Sciences, ASO San Luigi Orbassano-Torino, University of Torino, Torino, Italy and ${ }^{2}$ Department of Cardiac, \\ Thoracic and Vascular Sciences, University of Padova, Padova, Italy \\ (Correspondence should be addressed to C Scaroni; Email: carla.scaroni@unipd.it)
}

\begin{abstract}
Context: Appropriate glucocorticoid replacement therapy in adrenal insufficiency (AI) is crucial, given the risks of chronic under- or overtreatment, particularly in patients on multiple medications. Salivary sampling allows for non-invasive, stress-free cortisol measurement.

Objective: To determine whether salivary cortisol measurement is helpful in assessing the adequacy of glucocorticoid therapy with cortisone acetate (CA) in patients with secondary AI.

Design: A prospective cohort study at the Endocrinology Unit of Padua University Hospital.

Methods: Six samples of salivary cortisol were collected from 28 patients with secondary AI on CA treatment and from 36 healthy volunteers at fixed times of the day, and used to calculate salivary cortisol levels at each time point and the area under the curve (AUC) across the different sampling times.

Results: Salivary cortisol levels were lower in patients than in controls in the morning but no differences were found in the afternoon or at night before resting. Salivary cortisol levels were higher in patients immediately following CA administration. Ten patients showed an AUC above the 97.5th percentile of controls, without clinical signs of hypercortisolism, and salivary cortisol levels $90 \mathrm{~min}$ after each dose of CA predict the AUC. All patients had severe GH deficiency and there were no differences in salivary cortisol levels or AUC between patients treated or not with GH.

Conclusions: Two salivary cortisol determinations, able to predict the daily AUC, may allow for assessing the adequacy of glucocorticoid replacement therapy in secondary AI and for identifying cases of overor undertreatment.
\end{abstract}

European Journal of Endocrinology 167 769-776

\section{Introduction}

Optimizing glucocorticoid replacement therapy in adrenal insufficiency (AI) is a clinical challenge because undertreatment may lead to acute frank AI or chronic fatigue, while chronic glucocorticoid excess may cause obesity, hypertension, diabetes, and osteoporosis (1). Optimal replacement should produce cortisol concentrations that mirror the circadian cortisol rhythm (2), but available immediate-release glucocorticoid preparations only partially replicate the physiological cortisol profile (3); expertise with modified-release hydrocortisone $(\mathrm{HC})$ tablets is still inadequate $(4,5)$. Secondary AI coexists with other pituitary hormone deficiencies; their replacement therapies may interfere with glucocorticoid metabolism and action $(6,7,8,9)$. A number of methods (urinary free cortisol, serum cortisol, or clinical score) have been suggested for assessing the adequacy of glucocorticoid replacement, but there is no consensus about the most reliable in clinical practice $(1,3,10,11)$.
Salivary steroids are a non-invasive, easily repeated, stress-free way to measure circulating free hormone levels $(12,13)$, recently recommended for assessing cortisol profiles in healthy people $(14,15)$ and in patients with hypothalamic-pituitary-adrenal (HPA) axis disorders $(16,17)$.

$\mathrm{HC}$ may represent the most physiological replacement therapy, but even when it is given three times a day, the resulting serum cortisol profile only partially replicates the circadian cortisol rhythm of healthy people. Serum cortisol peaks after taking HC, and then drops to lower than normal levels before the next dose; there is no night-time rise, so patients wake up with very low cortisol levels that contribute to early morning fatigue, a major drawback of current replacement regimes (3, 18). Salivary cortisol assays have been suggested for assessing HC-based glucocorticoid replacement, but literature data differ in terms of its reliability $(19,20,21,22)$. Cortisone acetate (CA) is an oral glucocorticoid that needs hepatic conversion to 
cortisol by the enzyme $11 \beta$-hydroxysteroid dehydrogenase type 1 (11 $\beta$-HSD1). CA is more readily available than $\mathrm{HC}$ in Italy and other European countries, and is usually administered twice daily in secondary AI. On CA therapy, serum profiles seem to have lower cortisol peaks and also tends to decline more slowly than on HC therapy (18). One report has claimed that CA has metabolic advantages (on HbAlc and waistto-hip ratio (WHR)) over $\mathrm{HC}$, particularly in patients with hypopituitarism treated with recombinant human GH (rhGH) (23).

A more precise estimation of endogenous cortisol production rate, believed to be around $9-11 \mathrm{mg} / \mathrm{m}^{2}$ per day (24), has recently led to a reduction in the dosage of glucocorticoid replacement therapy $(1,2)$. How best to assess and adjust each patient's glucocorticoid therapy to avoid the risk of mild, but chronic under- or overtreatment remains, however, a matter of debate.

The aim of our study was to assess the daily cortisol profile in healthy subjects and patients with secondary AI being treated with CA by six sequential salivary cortisol determinations, with a view to establishing the reliability of this method for deciding each individual's dosage, and to examine the influence of rhGH replacement treatment.

\section{Materials and methods}

\section{Patients and protocol}

We recruited 28 outpatients with hypopituitarism, 17 male and 11 female (M/F ratio 1.5 , age $54 \pm 18$ years), from January to December 2010, at the Endocrinology Unit of Padua. Their clinical features and hormone replacement therapies are summarized in Table 1. Secondary AI was diagnosed clinically and confirmed biochemically (with basal serum morning cortisol under $138 \mathrm{nmol} / \mathrm{l}$ in 12 patients or inadequate cortisol response (considered as cortisol below $440 \mathrm{nmol} / \mathrm{l}$ ) to a standard or low-dose ACTH test (25) in the other 16 subjects), and the patients had been taking the same CA replacement dose for at least 6 months before enrollment. CA dose was first based upon the body surface area (BSA) and then adapted according to well-being of the patient, serum sodium/ potassium, blood pressure, glycemia, and urinary free cortisol levels. All patients had normal renal and liver function and showed no clinical or biochemical signs of iatrogenic hypercortisolism (e.g. newly diagnosed or worsening hypertension, obesity, impaired fasting glucose, hypokalemia, capillary fragility, or abdominal striae). None of the patients suffered from nausea,

Table 1 Clinical details of the patients.

\begin{tabular}{|c|c|c|c|c|c|}
\hline No. & Sex & Age & Hypopituitarism & Type of deficit & $\begin{array}{l}\text { Replacement } \\
\text { therapy }\end{array}$ \\
\hline 1 & $\mathrm{~F}$ & 47 & Empty sella & $A, T, G, S$ & $\mathrm{CA}, \mathrm{rhGH}, \mathrm{T}_{4}, \mathrm{ST}$ \\
\hline 2 & $\mathrm{M}$ & 65 & Post-RT & $\mathrm{A}, \mathrm{T}, \mathrm{G}, \mathrm{S}$ & $\mathrm{CA}, \mathrm{rhGH}, \mathrm{T}_{4}, \mathrm{ST}$ \\
\hline 3 & $\mathrm{~F}$ & 54 & Post-RT & $\mathrm{A}, \mathrm{T}, \mathrm{G}$ & $\mathrm{CA}, \mathrm{rhGH}, \mathrm{T}_{4}$ \\
\hline 4 & $\mathrm{M}$ & 58 & Post-surg + RT & $A, G$ & $\mathrm{CA}, \mathrm{rhGH}$ \\
\hline 5 & $\mathrm{M}$ & 39 & Empty sella & $A, T, G, S$ & $\mathrm{CA}, \mathrm{rhGH}, \mathrm{T}_{4}, \mathrm{ST}$ \\
\hline 6 & $\mathrm{~F}$ & 62 & Empty sella & $\mathrm{A}, \mathrm{T}, \mathrm{G}$ & $\mathrm{CA}, \mathrm{rhGH}, \mathrm{T}_{4}$ \\
\hline 7 & $\mathrm{M}$ & 48 & Post-surg + RT & $\mathrm{A}, \mathrm{T}, \mathrm{G}, \mathrm{S}$ & $\mathrm{CA}, \mathrm{rhGH}, \mathrm{T}_{4}, \mathrm{ST}$ \\
\hline 8 & $\mathrm{M}$ & 48 & Post-surg + RT & A, T, G, S & $\mathrm{CA}, \mathrm{rhGH}, \mathrm{T}_{4}, \mathrm{ST}$ \\
\hline 9 & $\mathrm{~F}$ & 52 & Post-surg + RT & $\mathrm{A}, \mathrm{T}, \mathrm{G}$ & $\mathrm{CA}, \mathrm{rhGH}, \mathrm{T}_{4}$ \\
\hline 10 & $M$ & 56 & Post-surg + RT & $A, T, G, S$ & $\mathrm{CA}, \mathrm{rhGH}, \mathrm{T}_{4}, \mathrm{ST}$ \\
\hline 11 & $\mathrm{M}$ & 45 & Post-surg & $A, T, G, S$ & $\mathrm{CA}, \mathrm{rhGH}, \mathrm{T}_{4}, \mathrm{ST}$ \\
\hline 12 & $\mathrm{~F}$ & 23 & Post-surg + RT & $A, T, G, S$ & $\mathrm{CA}, \mathrm{rhGH}, \mathrm{T}_{4}, \mathrm{ST}$ \\
\hline 13 & $\mathrm{~F}$ & 23 & Post-surg & $A, T, G, S$ & $\mathrm{CA}, \mathrm{rhGH}, \mathrm{T}_{4}, \mathrm{ST}$ \\
\hline 14 & $\mathrm{M}$ & 57 & Post-surg & $\mathrm{A}, \mathrm{T}, \mathrm{G}, \mathrm{S}$ & $\mathrm{CA}, \mathrm{rhGH}, \mathrm{T}_{4}, \mathrm{ST}$ \\
\hline 15 & $\mathrm{M}$ & 58 & Post-surg & $A, T, G, S$ & $\mathrm{CA}, \mathrm{rhGH}, \mathrm{T}_{4}, \mathrm{ST}$ \\
\hline 16 & $\mathrm{M}$ & 21 & Congenital hypoplasia & $\mathrm{A}, \mathrm{T}, \mathrm{G}$ & $\mathrm{CA}, \mathrm{rhGH}, \mathrm{T}_{4}$ \\
\hline 17 & $\mathrm{~F}$ & 24 & Congenital hypoplasia & $A, T, G, S$ & $\mathrm{CA}, \mathrm{rhGH}, \mathrm{T}_{4}, \mathrm{ST}$ \\
\hline 18 & $\mathrm{M}$ & 75 & Parasellar meningioma & $\mathrm{A}, \mathrm{T}, \mathrm{G}$ & $\mathrm{CA}, \mathrm{T}_{4}$ \\
\hline 19 & $\mathrm{~F}$ & 68 & Post-surg & $\mathrm{A}, \mathrm{T}, \mathrm{G}$ & $\mathrm{CA}, \mathrm{T}_{4}$ \\
\hline 20 & M & 72 & Post-surg & $\mathrm{A}, \mathrm{T}, \mathrm{G}, \mathrm{S}$ & $\mathrm{CA}, \mathrm{T}_{4}, \mathrm{ST}$ \\
\hline 21 & $\mathrm{~F}$ & 78 & Empty sella & $\mathrm{A}, \mathrm{T}, \mathrm{G}$ & $\mathrm{CA}, \mathrm{T}_{4}$ \\
\hline 22 & $M$ & 76 & Post-surg + RT & $A, T, G, S$ & $\mathrm{CA}, \mathrm{T}_{4}, \mathrm{ST}$ \\
\hline 23 & M & 66 & Post-surg & $\mathrm{A}, \mathrm{T}, \mathrm{G}, \mathrm{S}$ & $\mathrm{CA}, \mathrm{T}_{4}, \mathrm{ST}$ \\
\hline 24 & $\mathrm{~F}$ & 31 & Hydrocephalus & $\mathrm{A}, \mathrm{T}, \mathrm{G}$ & $\mathrm{CA}, \mathrm{T}_{4}$ \\
\hline 25 & $\mathrm{M}$ & 65 & Post-surg & $\mathrm{A}, \mathrm{T}, \mathrm{G}, \mathrm{S}$ & $\mathrm{CA}, \mathrm{T}_{4}, \mathrm{ST}$ \\
\hline 26 & $M$ & 58 & Post-surg & $A, T, G, S$ & $\mathrm{CA}, \mathrm{T}_{4}, \mathrm{ST}$ \\
\hline 27 & $M$ & 74 & Post-surg & A, T, G, S & $\mathrm{CA}, \mathrm{T}_{4}, \mathrm{ST}$ \\
\hline 28 & $\mathrm{~F}$ & 76 & Post-surg + RT & $\mathrm{A}, \mathrm{T}, \mathrm{G}$ & $\mathrm{CA}, \mathrm{T}_{4}$ \\
\hline
\end{tabular}

Surg, surgery; RT, radiotherapy; $A$, secondary adrenal insufficiency; $T$, secondary thyroid insufficiency; $G$, severe $\mathrm{GH}$ deficiency; S, secondary hypogonadism; $\mathrm{CA}$, cortisone acetate; rhGH, recombinant human $\mathrm{GH} ; \mathrm{T}_{4}$, levothyroxine; ST, sex hormone therapy. 
vomiting, diarrhea, intestinal pain, sleep disturbance, or headache over the last 6 months of replacement therapy, judging from their routinely recorded medical history. None of them had gastrointestinal disorders that might interfere with CA absorption (such as celiac disease or autoimmune gastritis). The mean daily dose of CA was $22.8 \pm 4.9 \mathrm{mg} /$ day (median 21.9; range 18.75-37.5), which corresponded on average to $12 \mathrm{mg} / \mathrm{m}^{2}$ of $\mathrm{CA}$ (the equivalent dose of $\mathrm{HC}$ is $9.6 \mathrm{mg} / \mathrm{m}^{2}$ ). All patients took CA twice a day, the major part of the daily dose in the morning at wake up and the lower in the afternoon; only a few patients received therapy divided into two equal doses (CA regimens: 13 patients $12.5+6.25 \mathrm{mg} /$ day, four patients $18.75+$ $6.25 \mathrm{mg} /$ day, two patients $25+6.25 \mathrm{mg}$ /day, two patients $25+12.5 \mathrm{mg} /$ day, and seven patients $12.5+12.5 \mathrm{mg} /$ day) .

GH deficiency (GHD) was confirmed in all patients by a GHRH + arginine stimulation test. We considered severe GHD when the GH peak was below cut-off limits based upon BMI: for BMI $<25 \mathrm{~kg} / \mathrm{m}^{2}$, a peak of $\mathrm{GH}$ $\leq 11.5 \mu \mathrm{g} / \mathrm{l}$; for BMI $25-30 \mathrm{~kg} / \mathrm{m}^{2}$, a peak of $\mathrm{GH}$ $\leq 8 \mu \mathrm{g} / \mathrm{l}$; for BMI $>30 \mathrm{~kg} / \mathrm{m}^{2}$, a peak of $\mathrm{GH} \leq 4 \mu \mathrm{g} / \mathrm{l}$ (26); IGF1 levels in patients receiving rhGH therapy were between the 50th and 97.5th percentile of normal controls matched for sex and age (27). The diagnosis of other hormone deficiencies (central hypothyroidism or hypogonadism) was based on low pituitary hormone levels with low serum free thyroxine $\left(\mathrm{fT}_{4}\right)$ or gonadal steroid hormones. Adequacy of replacement therapy was documented in all patients with secondary hypothyroidism by $\mathrm{fT}_{4}$ levels in the normal range, whereas estradiol levels in the range for the follicular phase in pre-menopausal-aged women and total testosterone levels in the normal range for adult men suggested an adequate substitutive therapy (estrogen replacement route was transdermal for two women and oral for other two women, whereas testosterone therapy was by long-acting injection for four men and transdermal for nine men).

In our patients, we measured weight, height, and waist and hip circumference. We calculated BMI as $\mathrm{kg} / \mathrm{m}^{2}$ (BMI $<25 n=16,25-30 n=11$, 30-35 $n=1$, 35-40 $n=1,>40 n=0$ ), WHR as waist/hip circumference (classifying patients with Canoy (28) value: female with WHR $\geq 0.8 n=3$, male with WHR $\geq 0.95$ $n=5)$, and BSA by the DuBois and DuBois formula $\left(0.007184 \times\right.$ weight $_{\mathrm{kg}}^{0.425} \times$ height $\left._{\mathrm{cm}}^{0.725}\right)(29)$.

Thirty-six healthy volunteers, 21 male and 15 female (M/F ratio 1.4, age $49 \pm 16$ years), matched for mean age, sex, BMI class $(<25 n=18,25-30 n=14,30-35$ $n=3$, 35-40 $n=1,>40 n=0$ ), mean WHR (female with WHR $\geq 0.8 n=5$, male with WHR $\geq 0.95 n=10$ ), and mean BSA, provided clinical data and saliva samples during a day of normal activity. None of them were taking exogenous glucocorticoids or drugs that might interfere with the HPA axis; female volunteers were not taking oral or transdermal contraceptives and were investigated in the early follicular phase of the menstrual cycle.

The study protocol was approved by our local ethics committee, and all patients and healthy controls gave written informed consent.

\section{Salivary sample collection and analyses}

Healthy volunteers and patients collected six salivary samples at home the first in the morning on waking (labeled F 0), then $1 \mathrm{~h}$ and $30 \mathrm{~min}$ (F 1.5), $7 \mathrm{~h} \mathrm{(F} \mathrm{7),} 8 \mathrm{~h}$ and $30 \mathrm{~min}$ (F 8.5), $12 \mathrm{~h} \mathrm{(F} \mathrm{12),} \mathrm{and} 14 \mathrm{~h} \mathrm{(F} \mathrm{14)} \mathrm{after.}$ Patients' F 0 and F 7 collections were obtained before the morning and afternoon CA doses (all patients received $C A$ at least $30 \mathrm{~min}$ before the meal). During the course of the day, each saliva sample was collected into cotton-based sampling devices contained inside plastic syringes using the Salivette commercial device (Sarstedt, Numbrecht, Germany). Patients and volunteers were advised to soak the absorbent cotton with saliva for 2 or $3 \mathrm{~min}$, with the sample then placed in a syringe and kept at $+4{ }^{\circ} \mathrm{C}$. Samples were collected at least 30 min before taking a meal or drink to avoid any source of food or blood contamination; patients and healthy volunteers brushed their teeth at least $30 \mathrm{~min}$ before collecting their saliva and avoided smoking or eating licorice on the day of saliva collection. After centrifugation, we obtained sufficient saliva volume in all samples (at least $1 \mathrm{ml}$ ), and then stored at $-20{ }^{\circ} \mathrm{C}$ until assay with a commercially available RIA kit (Radim, Rome, Italy). The assay sensitivity was $0.5 \mathrm{ng} / \mathrm{ml}$. The intra and inter assay variation was 3 and 9\% respectively. Regarding specificity, this cortisol assay does not show cross-reaction with cortisone, desoxycorticosterone, corticosterone, estradiol, testosterone, and 17 hydroxyprogesterone. Coefficients of variation in the high and in the low range were respectively of 7 and $4 \%$. To assess endogenous daily cortisol secretion in healthy controls and glucocorticoid exposure in patients, we computed the area under the curve (AUC) for salivary cortisol levels at the different time points with respect to the ground $\left(\mathrm{AUC}_{0-14}\right)$, according to the trapezoidal formula proposed by Pruessner et al. (30). We divided the day being examined into two different periods of $7 \mathrm{~h}$, called $\mathrm{AUC}_{0-7}$ (from $\mathrm{F} 0$ to $\mathrm{F} 7$ ) and $\mathrm{AUC}_{7-14}$ (from $\mathrm{F} 7$ to $\mathrm{F} 14$ ).

We considered the 2.5 th and 97.5 th percentiles of the $\mathrm{AUC}_{0-14}, \mathrm{AUC}_{0-7}$, and $\mathrm{AUC}_{7-14}$ in healthy subjects as lower and upper limits of normality, so patients were classed as undertreated if the $\mathrm{AUC}_{\mathrm{O}-14}$ was below the 2.5 th percentile of healthy controls or overtreated if it was above the 97.5 th percentile of healthy controls.

\section{Statistical analysis}

Proportions and rates were calculated for categorical data, and continuous data are presented as means and S.D., medians and ranges or percentiles (the percentile 
Table 2 Percentiles of salivary cortisol concentrations in $\mathrm{ng} / \mathrm{ml}$ and $\mathrm{AUC}_{0-14}$, $\mathrm{AUC}_{0-7}$, and $\mathrm{AUC}_{7-14}$ in patients with secondary $\mathrm{Al}$ and in healthy volunteers.

\begin{tabular}{|c|c|c|c|c|c|}
\hline & 2.5 & 25 & 50 & 75 & 97.5 \\
\hline \multicolumn{6}{|l|}{ F 0} \\
\hline Patients & 0.13 & 0.84 & 1.54 & 2.45 & 9.72 \\
\hline $\begin{array}{l}\text { Controls } \\
\text { F } 15\end{array}$ & 3.25 & 5.74 & 7.44 & 10.37 & 15.73 \\
\hline Patients & 1.81 & 5.82 & 11.52 & 15.88 & 25.82 \\
\hline Controls & 2.02 & 3.77 & 5.14 & 6.71 & 11.75 \\
\hline \multicolumn{6}{|l|}{ F 7} \\
\hline Patients & 0.19 & 1.10 & 2.31 & 3.94 & 8.73 \\
\hline Controls & 0.45 & 1.89 & 3.80 & 4.87 & 7.91 \\
\hline \multicolumn{6}{|l|}{ F 8.5} \\
\hline Patients & 0.80 & 2.33 & 5.50 & 8.96 & 22.99 \\
\hline Controls & 0.65 & 2.42 & 3.28 & 4.22 & 6.89 \\
\hline \multicolumn{6}{|l|}{ F 12} \\
\hline Patients & 0.63 & 2.08 & 3.09 & 9.55 & 13.00 \\
\hline Controls & 0.08 & 0.96 & 2.15 & 2.92 & 4.61 \\
\hline \multicolumn{6}{|l|}{ F 14} \\
\hline Patients & 0.53 & 1.26 & 2.11 & 3.08 & 6.31 \\
\hline Controls & 0.09 & 0.97 & 1.63 & 2.23 & 4.68 \\
\hline \multicolumn{6}{|l|}{$\mathrm{AUC}_{0-14}$} \\
\hline Patients & 1339 & 3536 & 4860 & 6759 & 10374 \\
\hline Controls & 1180 & 2064 & 3073 & 4107 & 5926 \\
\hline \multicolumn{6}{|l|}{$\mathrm{AUC}_{0-7}$} \\
\hline Patients & 865 & 1755 & 3071 & 3886 & 6172 \\
\hline Controls & 817 & 1479 & 2100 & 2722 & 3943 \\
\hline \multicolumn{6}{|l|}{$\mathrm{AUC}_{7-14}$} \\
\hline Patients & 488 & 1109 & 1850 & 3020 & 5315 \\
\hline Controls & 165 & 753 & 1114 & 1533 & 1997 \\
\hline
\end{tabular}

is the value that divides the distribution in such a way that a specific percentage of data is less than or equal to the defined percentile), calculated with the National Institute of Standards and Technology (NIST) formula. Groups were compared by the $\chi^{2}$ test for categorical variables and by the Wilcoxon rank sum test for quantitative variables. To take into account multiple comparisons, the raw $P$ values in group comparisons for the salivary samples at fixed times and AUC obtained with Wilcoxon test were adjusted with Bonferroni's method. Linear regression analysis was used to examine the relationship between salivary cortisol $\mathrm{F} 1.5$ and $\mathrm{AUC}_{0-7}$, and between $\mathrm{F} 8.5$ and $\mathrm{AUC}_{7-14}$. The database was managed and statistical analysis performed by SAS 9.1 for Windows (SAS Institute, Inc., Cary, NC, USA) or Excel 2010 for Windows. Significance level was set as $P<0.05$ for all tests.

\section{Results}

Percentiles of the six daily salivary cortisol assays, and $\mathrm{AUC}_{0-14}, \mathrm{AUC}_{0-7}$, and $\mathrm{AUC}_{7-14}$ for healthy volunteers and patients are shown in Table 2 . We considered the 2.5th and 97.5th percentiles of $\mathrm{AUC}_{0-14}, \mathrm{AUC}_{0-7}$, and $\mathrm{AUC}_{7-14}$ in the healthy controls as the lower and upper limits of normality.

Each patient's salivary cortisol levels are shown in Fig. 1. Their F 0 levels were lower than those in controls $(P<0.0001)$ except for four patients with some residual glucocorticoid activity; F 1.5, F 8.5, and F 12 levels were higher in patients than in controls $(P<0.001$, $P<0.05$, and $P<0.01)$. There were no differences between patients and controls in F 7 and F 14 samples. $\mathrm{AUC}_{0-14}$ was significantly higher in patients than in controls $(P<0.01)$.

Stratifying the patients by BMI (above or below $25 \mathrm{~kg} / \mathrm{m}^{2}$ ) or sex, we found no differences between the

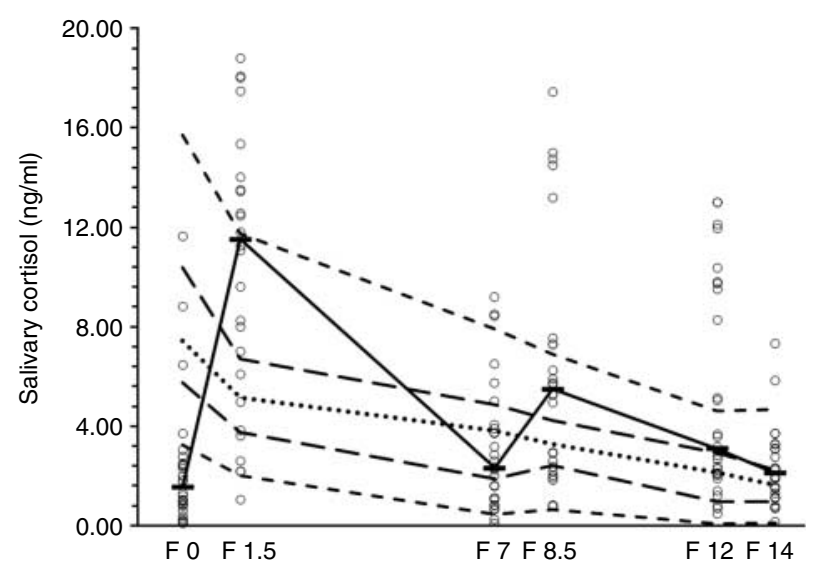

Figure 1 Salivary cortisol concentrations in patients and in controls. Open circles indicate salivary cortisol concentrations in patients and the solid black line indicates their median salivary cortisol levels. Percentiles of salivary cortisol in healthy controls are: 2.5 th and 97.5th percentiles, short broken lines; 25th and 75th percentiles, longer broken lines; 50th percentile, dotted line. 

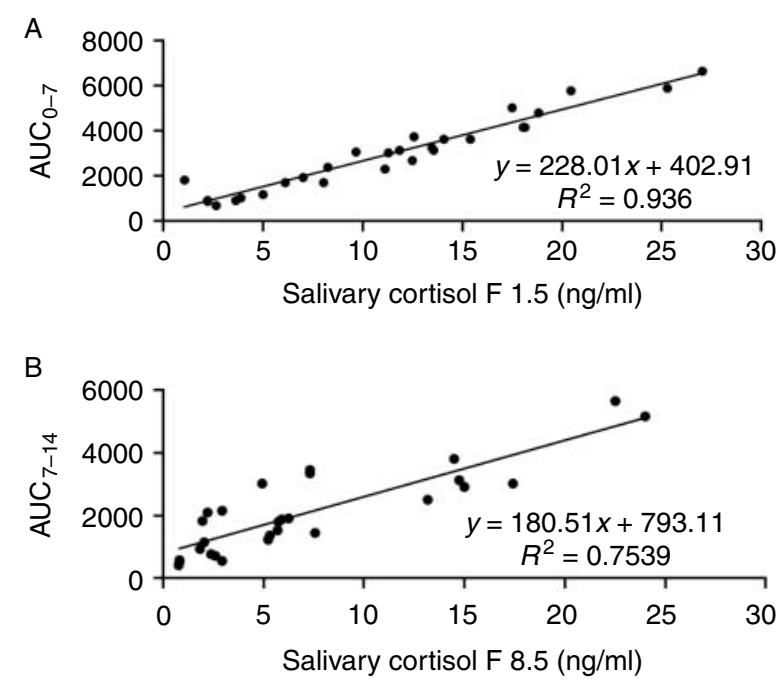

Figure 2 (A) Logistic regression between salivary cortisol F 1.5 and $\left.\mathrm{AUC}_{0-7} ; \mathrm{B}\right)$ logistic regression between salivary cortisol $\mathrm{F} 8.5$ and $\mathrm{AUC}_{7-14}$.

groups in terms of single salivary cortisol concentrations, $\mathrm{AUC}_{0-14}, \mathrm{AUC}_{0-7}$, or $\mathrm{AUC}_{7-14}$. There were no correlations between BMI, WHR, or BSA with the CA dose.

None of the patients had an $\mathrm{AUC}_{\mathrm{O}-14}$ for salivary cortisol below the normal range (considered as the 2.5 th percentile of controls), but 10 of the 28 patients (36\%) had an $\mathrm{AUC}_{0-14}$ above the 97.5th percentile of normal subjects, with no clear signs or symptoms of glucocorticoid excess. These patients also had higher F 1.5 and F 8.5 salivary cortisol levels than the other patients (F 1.5 median 18.05, range 8.23-27.00 vs median 7.50 , range $1.91-14.62 \mathrm{ng} / \mathrm{ml}, P<0.001$; $\mathrm{F}$ 8.5 median 10.24 , range $4.95-24.00$ vs median 2.77 , range $0.16-7.35 \mathrm{ng} / \mathrm{ml}, P<0.01$ ), while there was no difference in F 0, F 7, and F 14 median salivary cortisol levels, BMI, BSA, or WHR.

Whenever the patients' $\mathrm{F} 1.5$ salivary levels were above $11.75 \mathrm{ng} / \mathrm{ml}$ (the 97.5th percentile of controls), there was a $90 \%$ probability of their $\mathrm{AUC}_{0-7}$ being above the 97.5th percentile of normal subjects $\left(\chi^{2}=9.9556\right.$, $P<0.001)$, and logistic regression predicted $94 \%$ of $\mathrm{AUC}_{0-7}\left(R^{2}\right.$ 0.94, $\mathrm{P}<0.0001$; Fig. 2A). Whenever the F 8.5 salivary cortisol levels were above $6.89 \mathrm{ng} / \mathrm{ml}$ (97.5th percentile of controls), there was a $70 \%$ probability of their $\mathrm{AUC}_{7-14}$ being high as well (Fisher's exact test $P<0.01$ ), and logistic regression predicted $75 \%$ of $\mathrm{AUC}_{7-14}\left(R^{2} 0.75, P<0.0001\right.$; Fig. 2B).

All patients were with severe GHD, but only 17 were treated with rhGH. The salivary cortisol levels in patients divided into two groups according to whether or not they were on rhGH treatment are shown in Fig. 3. We found no significant differences in salivary cortisol concentrations, $\mathrm{AUC}_{\mathrm{O}-14}, \mathrm{AUC}_{0-7}$, or $\mathrm{AUC}_{7-14}$ between these two groups of patients, but we found that the F 1.5 values were higher in untreated patients than in those taking rhGH replacement therapy, although the difference did not reach statistical significance (Wilcoxon test $P=0.07$, adjusted with Bonferroni's method $P=0.66)$.

\section{Discussion}

Treating primary or secondary AI appropriately remains a challenge, because there is no consensus on how to titrate the dosage of replacement therapy to produce cortisol levels that mirror the physiological circadian rhythm and to avoid the risk of chronic underor over-treatment $(1,2)$.

Several tools have been proposed to evaluate the adequacy of glucocorticoid replacement therapy, but they all have their weakness. Urinary free cortisol excretion fails to detect daily fluctuations of cortisol and reveals a marked day-to-day variability depending on renal tubular function $(1,10)$. A clinical score was proposed by Arlt et al. (11), but subsequent studies did not support the superiority of this qualitative system over quantitative methods. Mah et al. (3) suggested a single serum cortisol measurement $4 \mathrm{~h}$ after administering $\mathrm{HC}$, comparing the results with normative data, but the study involved only a few patients and has not been replicated in patients taking CA. Some studies have methodological weakness, such as the lack of appropriate control group or the involvement of patients with both primary and secondary AI, with some endogenous cortisol secretion in the latter $(3,11,18)$.

Salivary cortisol is a useful tool for studying disorders of the HPA axis (16) and has been previously proposed as a method for assessing glucocorticoid replacement therapy in AI $(12,13,14)$. Some authors have found it to be less useful to measure salivary cortisol in patients taking HC replacement therapy $(19,20)$, though no formal comparison of salivary cortisol levels was drawn between patients and healthy controls in these studies.

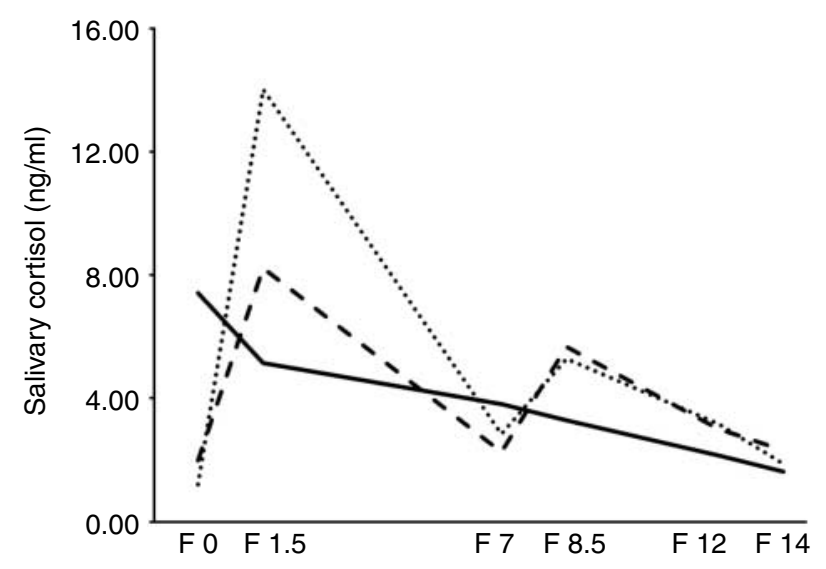

Figure 3 Median salivary cortisol concentration of healthy subjects (solid line), compared with patients treated with (broken line, $n=17$ ) or without (dotted line, $n=11$ ) rhGH replacement therapy. 
Løvås \& Husebye (21) measured salivary cortisol levels in patients with Addison's disease receiving a s.c. continuous infusion of $10 \mathrm{mg} / \mathrm{m}^{2}$ per day of $\mathrm{HC}$ with a view to replicating the diurnal rhythm, which is not a practical approach for use in outpatients. To our knowledge, there is to date no agreement on monitoring glucocorticoid therapy and titrating its dosage $(1,2)$, in particular when CA is used as replacement therapy.

We obtained six different saliva collections from healthy controls and patients with secondary AI in order to divide the day into two periods of comparable length. We calculated the percentiles of normal cortisol concentrations at any time point and the AUC, a mathematical method for representing the integrated daily cortisol production in the normal population and the 24-h exposure to exogenous cortisol in patients with AI, with an acceptable degree of approximation. The median salivary cortisol concentrations and their AUC for patients were between the 2.5th and 97.5th percentiles of healthy controls, likely because we administered the modern low-dose glucocorticoid replacement therapy. Even though these data could reflect an adequate replacement, salivary cortisol peak concentration in patients measured $1.5 \mathrm{~h}$ after CA intake was higher than salivary cortisol levels in healthy controls at the same time. The modern once-daily $\mathrm{HC}$ dual-release tablet probably achieved a cortisol profile more similar to healthy subjects, but there is less evidence and was found only in primary AI patients treated with this therapy (31). In healthy subjects, the salivary cortisol assays reproduced the physiological circadian rhythm of cortisol levels, with higher concentrations in the morning that slowly decreased in the hours thereafter and were nearly halved at night. The salivary cortisol curve recorded in healthy controls was compared with patients with secondary AI taking CA in two fixed doses. If the patients' salivary cortisol levels on waking were lower than the 2.5 th percentile of healthy controls, we could use this cut-off to indicate AI, as recently proposed by Deutschbein et al. (17), even though a few of our patients have some residual glucocorticoid activity, as expected in secondary AI. There was no difference between patients and controls in the $\mathrm{F} 7$ levels, meaning that patients maintained an adequate glucocorticoid exposure in the middle of the day after a fixed dose of CA $\left(12 \mathrm{mg} / \mathrm{m}^{2}\right.$ of CA, equivalent to a $\mathrm{HC}$ dose of $9.6 \mathrm{mg} / \mathrm{m}^{2}$ ). Since a normal night-time cortisol value excludes hypercortisolism (32), the F 14 salivary cortisol could be a useful marker of glucocorticoid excess in AI. Our patients on CA had lower peak values and a slower decline in cortisol levels than the patients treated with HC, as described by Mah et al. (3), though we acknowledge the limited value of comparing results obtained in different studies. Should this finding be confirmed in a larger series, however, it could represent an advantage of CA therapy, coinciding with fewer adverse events due to acute hypercortisolism (hypertension, hyperglycemia).
In our series of patients, we found no correlation between BMI, WHR, or BSA with the CA dose, probably due to the limited number of our series of patients.

None of our patients had a salivary cortisol $\mathrm{AUC}_{0-14}$ below the 2.5th percentile of healthy controls, so we can assume that none of our patients were undertreated. Ten of the 28 patients ( $36 \%$ ) showed an $\mathrm{AUC}_{0-14}$ above the 97.5th percentile, albeit without any overt signs or symptoms of hypercortisolism, and we judged these patients to be overtreated. The AUC may be a reliable tool for assessing daily exposure to exogenous glucocorticoids, but it is laborious and impractical in routine clinical practice. We could suggest a simplified assessment based on only two saliva collections, reflecting the close correlation between F 1.5 and F 8.5 salivary cortisol levels and the AUC, both of which enabling the same distinction between well- and overtreated patients. Salivary cortisol samples collected $1 \mathrm{~h}$ and $30 \mathrm{~min}$ after the morning and afternoon doses of CA could pinpoint the majority of overtreated patients (90 and 70\%, based on the morning and afternoon doses respectively).

Another point to note concerns co-treatment with rhGH: $11 \beta$-HSD1 activity is enhanced in GHD, leading to a higher tissue exposure to glucocorticoids, so there may be differences in cortisol exposure in patients treated with $\mathrm{CA}$ or $\mathrm{HC}$ in association with rhGH therapy, which inhibits the metabolism of cortisone into cortisol $(8,9,23)$. In secondary AI, other replacement therapies (rhGH or gonadal steroid hormones) may raise cortisolbinding globulin levels, another reason for the superiority of salivary measurements to assess cortisol profiles in secondary $\mathrm{AI}(7,8,9)$. We showed that salivary cortisol levels after the morning dose of CA were higher in patients with GHD not treated with rhGH (though not to a statistically significant degree in our sample, possibly because of its limited size or of a random effect). Further studies in a larger series of patients with GHD not taking rhGH are needed to confirm whether these patients should be treated with lower doses of CA.

In summary, we assessed the circadian cortisol profile by means of multiple round-the-clock salivary cortisol collections from healthy controls and patients taking CA for secondary AI. Our study cannot support any general hypotheses due to the limited sample size and the lack of any long-term follow-up to assess the clinical impact of dose titration based on our data. On the other hand, the number of salivary collections can be restricted to just 2 per day, because cortisol levels measured $1 \mathrm{~h}$ and 30 min after each CA dose adequately predicts the whole daily curve. These results thus pave the way to a future application of salivary cortisol assays for assessing the adequacy of replacement therapy in outpatients with secondary AI.

\section{Declaration of interest}

The authors declare that there is no conflict of interest that could be perceived as prejudicing the impartiality of the research reported. 


\section{Funding}

The study was not supported financially in any way.

\section{References}

1 Debono M, Price JN \& Ross RJ. Novel strategies for hydrocortisone replacement. Best Practice $\mathcal{E}$ Research. Clinical Endocrinology E Metabolism 200923 221-232. (doi:10.1016/j.beem.2008. 09.010)

2 Grossman AB. The diagnosis and management of central hypoadrenalism. Journal of Clinical Endocrinology and Metabolism 201095 4855-4863. (doi:10.1210/jc.2010-0982)

3 Mah PM, Jenkins RC, Rostami-Hodjegan A, Newell-Price J, Doane A, Ibbotson V, Tucker GT \& Ross RJ. Weight-related dosing. timing and monitoring hydrocortisone replacement therapy in patients with adrenal insufficiency. Clinical Endocrinology 200461 367-375. (doi:10.1111/j.1365-2265.2004.02106.x)

4 Newell-Price J, Whiteman M, Rostami-Hodjegan A, Darzy K, Shalet S, Tucker GT \& Ross RJ. Modified-release hydrocortisone for circadian therapy: a proof-of-principle study in dexamethasonesuppressed normal volunteers. Clinical Endocrinology $2008 \mathbf{6 8}$ 130-135. (doi:10.1111/j.1365-2265.2007.03011.x)

5 Verma S, Vanryzin C, Sinaii N, Kim MS, Nieman LK, Ravindran S, Calis KA, Arlt W, Ross RJ \& Merke DP. A pharmacokinetic and pharmacodynamic study of delayed- and extended-release hydrocortisone (Chronocort) vs conventional hydrocortisone (Cortef) in the treatment of congenital adrenal hyperplasia. Clinical Endocrinology 201072 441-447. (doi:10.1111/j.1365-2265.2009.03636.x)

6 Porretti S, Giavoli C, Ronchi C, Lombardi G, Zaccaria M, Valle D, Arosio M \& Beck-Peccoz P. Recombinant human GH replacement therapy and thyroid function in a large group of adult GH-deficient patients: when does L-T(4) therapy become mandatory? Journal of Clinical Endocrinology and Metabolism 200287 2042-2045. (doi:10.1210/jc.87.5.2042)

7 Agha A \& Monson JP. Modulation of glucocorticoid metabolism by the growth hormone - IGF-1 axis. Clinical Endocrinology $2007 \mathbf{6 6}$ 459-465. (doi:10.1111/j.1365-2265.2007.02763.x)

8 Scaroni C, Ceccato F, Rizzati S \& Mantero F. Concomitant therapies (glucocorticoids and sex hormones) in adult patients with growth hormone deficiency. Journal of Endocrinological Investigation 2008 $3161-65$.

9 Filipsson H \& Johannsson G. GH replacement in adults: interactions with other pituitary hormone deficiencies and replacement therapies. European Journal of Endocrinology 2009 161 S85-S95. (doi:10.1530/EJE-09-0319)

10 Monson JP. The assessment of glucocorticoid replacement therapy. Clinical Endocrinology 199746 269-270. (doi:10.1046/j.13652265.1997.87897.x)

11 Arlt W, Rosenthal C, Hahner S \& Allolio B. Quality of glucocorticoid replacement in adrenal insufficiency: clinical assessment vs timed serum cortisol measurements. Clinical Endocrinology 2006 64 384-389. (doi:10.1111/j.1365-2265.2006.02473.x)

12 Garde AH \& Hansen AM. Long-term stability of salivary cortisol. Scandinavian Journal of Clinical and Laboratory Investigation 2005 65 433-436. (doi:10.1080/00365510510025773)

13 Lewis JG. Steroid analysis in saliva: an overview. Clinical Biochemist. Reviews 200627 139-146.

14 Lederbogen F, Kühner C, Kirschbaum C, Meisinger C, Lammich J, Holle R, Krumm B, Von Lengerke T, Wichmann HE, Deuschle M et al. Salivary cortisol in a middle-aged community sample: results from 990 men and women of the KORA-F3 Augsburg study. European Journal of Endocrinology 2010 163 443-451. (doi:10. 1530/EJE-10-0491)

15 Noordam R, Jansen SW, Akintola AA, Oei NY, Maier AB, Pijl H, Slagboom PE, Westendorp RG, van der Grond J, de Craen AJ et al. Familial longevity is marked by lower diurnal salivary cortisol levels: the Leiden Longevity Study. PLoS ONE 20127 e31166. (doi:10.1371/journal.pone.0031166)
16 Raff $\mathrm{H}$. Utility of salivary cortisol measurements in Cushing's syndrome and adrenal insufficiency. Journal of Clinical Endocrinology and Metabolism 200994 3647-3655. (doi:10.1210/jc. 2009-1166)

17 Deutschbein T, Broecker-Preuss M, Flitsch J, Jaeger A, Althoff R, Walz MK, Mann K \& Petersenn S. Salivary cortisol as a diagnostic tool for Cushing's syndrome and adrenal insufficiency: improved screening by an automatic immunoassay. European Journal of Endocrinology 201266 613-618. (doi:10.1530/EJE-11-0945)

18 Bleicken B, Hahner S, Loeffler M, Ventz M, Allolio B \& Quinkler M. Impaired subjective health status in chronic adrenal insufficiency: impact of different glucocorticoid replacement regimens. European Journal of Endocrinology $2008159811-817$. (doi:10.1530/EJE08-0578)

19 Wong V, Yan T, Donald A \& McLean M. Saliva and bloodspot cortisol: novel sampling methods to assess hydrocortisone replacement therapy in hypoadrenal patients. Clinical Endocrinology 200461 131-137. (doi:10.1111/j.1365-2265.2004. 02062.x)

20 Maguire AM, Ambler GR, Moore B, Waite K, McLean M \& Cowell CT. The clinical utility of alternative, less invasive sampling techniques in the assessment of oral hydrocortisone therapy in children and adolescents with hypopituitarism. European Journal of Endocrinology 2007156 471-476. (doi:10.1530/EJE-06-0700)

21 Løvås K \& Husebye ES. Continuous subcutaneous hydrocortisone infusion in Addison's disease. European Journal of Endocrinology 2007157 109-112. (doi:10.1530/EJE-07-0052)

22 Thomson AH, Devers MC, Wallace AM, Grant D, Campbell K, Freel M \& Connell JM. Variability in hydrocortisone plasma and saliva pharmacokinetics following intravenous and oral administration to patients with adrenal insufficiency. Clinical Endocrinology 200766 789-796. (doi:10.1111/j.1365-2265.2007.02812.x)

23 Filipsson H, Monson JP, Koltowska-Häggström M, Mattsson A \& Johannsson G. The impact of glucocorticoid replacement regimens on metabolic outcome and comorbidity in hypopituitary patients. Journal of Clinical Endocrinology and Metabolism 200691 3954-3961. (doi:10.1210/jc.2006-0524)

24 Kraan GP, Dullaart RP, Pratt JJ, Wolthers BG, Drayer NM \& De Bruin R. The daily cortisol production reinvestigated in healthy men. The serum and urinary cortisol production rates are not significantly different. Journal of Clinical Endocrinology and Metabolism 199883 1247-1252. (doi:10.1210/jc.83.4.1247)

25 Kazlauskaite R, Evans AT, Villabona CV, Abdu TA, Ambrosi B, Atkinson $\mathrm{AB}$, Choi $\mathrm{CH}$, Clayton RN, Courtney $\mathrm{CH}$, Gonc EN et al. Corticotropin tests for hypothalamic-pituitary-adrenal insufficiency: a metaanalysis. Journal of Clinical Endocrinology and Metabolism 200893 4245-4253. (doi:10.1210/jc.2008-0710)

26 Ho KK \& on behalf of the GH Deficiency Consensus Workshop Participants. Consensus guidelines for the diagnosis and treatment of adults with GH deficiency II: a statement of the $\mathrm{GH}$ Research Society in association with the European Society for Pediatric Endocrinology, Lawson Wilkins Society, European Society of Endocrinology, Japan Endocrine Society, and Endocrine Society of Australia. European Journal of Endocrinology 2007157 695-700. (doi:10.1530/EJE-07-0631)

27 Friedrich N, Alte D, Volzke H, Spilcke-Liss E, Ludemann J, Lerch MM, Kohlmann T, Nauck M \& Wallaschofski H. Reference ranges of serum IGF-1 and IGFBP-3 levels in a general adult population results of the Study of Health in Pomerania (SHIP). Growth Hormone \& IGF Research 200818 228-237. (doi:10. 1016/j.ghir.2007.09.005)

28 Canoy D. Distribution of body fat and risk of coronary heart disease in men and women. Current Opinion in Cardiology 200823 591-598. (doi:10.1097/HCO.0b013e328313133a)

29 Sawyer M \& Ratain MJ. Body surface area as a determinant of pharmacokinetics and drug dosing. Investigational New Drugs 200119 171-177. (doi:10.1023/A:1010639201787)

30 Pruessner JC, Kirschbaum C, Meinlschmid G \& Hellhammer DH. Two formulas for computation of the area under the curve 
represent measures of total hormone concentration versus timedependent change. Psychoneuroendocrinology 200328 916-931. (doi:10.1016/S0306-4530(02)00108-7)

31 Johannsson G, Nilsson AG, Bergthorsdottir R, Burman P, Dahlqvist P, Ekman B, Engström BE, Olsson T, Ragnarsson O, Ryberg $\mathrm{M}$ et al. Improved cortisol exposure-time profile and outcome in patients with adrenal insufficiency: a prospective randomized trial of a novel hydrocortisone dual-release formulation. Journal of Clinical Endocrinology and Metabolism 201297 473-481. (doi:10.1210/jc.2011-1926)
32 Nieman LK, Biller BM, Findling JW, Newell-Price J, Savage MO, Stewart PM \& Montori VM. The diagnosis of Cushing's syndrome: an Endocrine Society Clinical Practice Guideline. Journal of Clinical Endocrinology and Metabolism 200893 1526-1540. (doi:10. 1210/jc.2008-0125)

Received 18 June 2012

Revised version received 4 September 2012

Accepted 3 October 2012 